\title{
[ 417$]$
}

\section{IV.}

\section{BESCHREIBUNG}

ciner Meeresfonde oder eines Bathometers, mic dem fuch jede Tiefe des Meeres meffen lüfst;

$$
\text { von }
$$

A. van Stipriann Luiscius,

Med. Dro und Lector der Chemie zu Delfe.

$D_{\text {iefes ift der Titel eines vor Kurzem erfchienenen }}$ Werkes, welches der Verfaffer allen Seemāchten der policirten Welt zugeeignet, und aber das Herr L'Evè que, Mitglied des Infituts und Examinator der Marine, der erften lílafle des Inftituts von reich einen bericht erftattet hat, aus welchem ich Frankclas, was man hier findet, grölsten Theils ausziehe.

Es fehlt uns faft noch ganz an Kenntniffen nher die Natur und Geftaltung des Bettes der verfchiedenen Meere. Unftreitig hat der Grund des Oceans eben fo gut feine Gebirge, Ebenen und Thäler, als der fichtbare Thejl der Erdnache; wir küonen fic nur durch cine grolse MJenge von Keihen von Verfuchen uber die Tiefe der Meere ksnnen lernen, zu denen die vereinte Bemühung mehrerer Níationen und die Unterfützung der Regierungen uns allein verbelfen künnen. 


\section{$\left[\begin{array}{lll}418 & \text { [ }\end{array}\right]$}

Man findet in einigen Reifebefchreibungen und in andern Schriften die vergeblichen Verfuche erzählt, welche zu verfchiedenen Zeiten gemacht worden find, um die Tiefe des Meeres, wenn fie eine gewilfe Grenze uberlteigt, mit der Sonde zu erforfchen. Es wird zwar gefagt, einige holländi: fche Seefahrer hätten von den europäilchen Kuften an bis auf die'Banls von New - Foundland immerfort Grund gefunden; die nöthigen Nachiveifungen feh. len aber hierüber. Auch der fel. Ba ache hatte an einigen der Hauptpunkte das Meer fondirt, und diefe Sondirungen zugleich mit denen, welche er bei andera vorfand, in einer Karte neuer Art zufammen geftellt, auf die er fein Syftem über diefen wichtigen Theil der Phyfik gründete; feine Arbeit ift aber von andern nicht fortgefetzt worden. Die gröfste Meerestiefe, welche man bis jetzt gemeffen hat, ohne Grund zu finden, betrug 1200 Klafter; Borda redet von ihr. In der Reife des Kapitains Phipps zum Nordpole findet man Sondirungen von $61 \overline{5}$ und 780 Klaftern, und ähnliche bei vielen andern.

Einige find der Meinung gewefen, es liege mehr an der Art, wie than die Meerestiefe fondi. re, als an der Unergründlichkeit des Meeres felbft, dafs man mit Sonilen von folclser Länge keinen Grund gefunden babe. Unter andern Buffon, der fich daruber folgender Maisen äulsert: „Um „die Tiefe des Meeres zu fondiren, dient gewühn"lich ein 30 bis 40 Pfund fchweres Stück Blei, 


\section{[ 419 ]}

„das an einem dünnen Seile befeftigt ift. Für „nicht allzu grofse Tiefen ift diefe Vorrichtung "zweckmälsig; bei fehr grofsen Tiefen kann fie da"gegen in Irrthum führen, und machen, dafs man "da keinen Grund findet, wo man ihn doch finden „follte. Denn da diefe Schnur fpecififch leichter , als das Waffer ift, fo kommt man, wenn viel "Schnur abgewickelt ift, endlich dahin, dafs das "Gewicht und die Schnur, zufammen genommen, "nicht mehr wiegen, als das Waffervolumen, wel"ches fie aus der Stelle drücken. So bald das der „Fall ift, finkt die Sonde nicht mehr, fondern „entfernt, in einerlei Tiefe fchivimmend, fich "feitwärts. Man müfste fich daher eiferner Ket„ten, oger anderer Körper, die fpecififch fchwe„rer als Waffer find, zu Sondirungen folcher Tie"fen bedienen. Es ift fehr wahrfeheinlich, dafs "hierin der Grund liegt, dafs Seefahrer an fo vie"len Orten im Meere keinen Grund gefunden ha„ben." Auch Bouguer war Anfangs diefer Mei* nung; er erkannte fie aber in der Folge als irrig. Hat nämlich die Schnur der Soncle fich mit Waffer durchzogen, fo ift fie fpecifich fchwerer als das Meerwafler, und die Sonde hat dann immer ein bedeutend gröfseres Gewicht, als ein gleich grofses Volumen Waffer; und eben aus diefem Ueberfchulfe an fpecififchem Gewichte ent?pringt ein Theil der Schwierigkeiten bei dem Sondiren. B ou guer, der diefe Schwierigkeiten fehr gut darftellt, hat einige Vorfchläge gethan, um ihnen abzuhelfen; 


\section{$\left[\begin{array}{lll}420 & ]\end{array}\right.$}

doch fcheint ihm die Sache immer äufserft fchwierig zu bleiben. Herr von Fleurieu fchlug vor, die Schnur aus Pferdehaaren zu verfertigen, danit fie einerlei fpecififches Gewicht mit, dem Waffer habe, und immer nur das Gewicht des Bleies allein die Sonde herab ziehe. Doch auch dann würden moch die gröfsten Hinderniffe bei Sondirungen in grolser Tiefe beftehen, dafs nämlich die Schnur bald zu kurz ift, bald bei unrubigem Meere zerreifst.

Dicfe Schwierigkeiten hatten fchon früher Naturforfcher beftimmt, auf andere Einrichtungen zu denken, nit denen fich die grolsen Tiefen des Meeres ficherer und leichter meflen liefsen. Alle von ihnen zu dem Ende in Vorfchlag gebrachten Bachometer find darin einander ähnlich, dafs fie aus zwei Stücken beftehen, von denen das eine fpecitich fchwerer, das andere fpeciffch leichter als das Meerwalfer ift; dafs beide Stücke verbunden im Waffer finken, bis fie auf dem Boden ankommen, hier aber fich von einander trennen; und dafs lann das fpecifich Leichtere zu der Oberfläche wiede $e_{-}$herauf fteigt, fo wie ein Luftballon in der Atmofphäre aufwärts fchwimmt. Diefe Bathometer beruben daher auf einerlei Princijp, und weichen nur in der mehr oder weniger glucklichen Art der Ausfuhrung von ejnander ab.

Der gelehrte und fcharffinnige Dr. Hooke fcheint der erfte gewefen zu feyn, der ein Batho. meter diefer Art vorgefchlagen hat. Es beftand 


\section{$\left[\begin{array}{lll}421 & 3\end{array}\right.$}

aus einer gut gefirnifsten hölzernen Kugel, mit einer gekrümmten Stahlfeder, an die ein Stück Blei, Eifen oder Stein, mittelft eines Hakens, gehängt wurde. Diefes Gewicht zog die Kugel mit herab; beim Auffofsen auf den Boden löfete fich die Feder aus, und die Kugel ftieg wieder aufwärts. Man beobachtete mit einer Sekundenuhr die Zeit, welche bis zum Wiedererfcheinen der Kugel binging. Varenius hat in feiner Geographie eine liurze Befchreibung diefes Bathometers und das Detail der Verfuche eingerückt, die damit zu Shernefs angeftellt wurden. Nachmahls verbefferte cier Dr. Hooke diefes Inftrument, und verfah es mit Flügeln nach Art der Windmühlen und mit Rüderwerk, um den herabwärts oder heraufwärts durchlaufenen Weg zu meffen. Man findet es befchrieben in feinen Philofophical Experiments and Obfervations, welche Derham 1726 zu London bekannt gemacht hat, unter der Ueberfchrift: $E x$ plorator profunditatis. Rochon hat auf feiner Reife nach Oftindien von einem Bathometer Gebrauch gemacht, das dem erften des Dr. Hooke ähnlich war, nur ftatt der Kagel eine Spindel hatte; feine Verfuche mifslangen und er giebt davon die Urfache an ${ }^{*}$ ). Ein ïhnliches Inftrument wird

") Dr. Hooke batte diefen feinen erften Vorfchlag felbft als unbrauchbar verworfen, weil es nicht möglich ift, den Schwimmer in dem Augenblicke gewiahr zu werden, wenn er aus dem Walfer wieder heratls taucht. Dafür theilte Dr. Hoo ke der Londner Societit in J. Ifol drei andere Vorfchläge zu Batlometern und andern luftrumenten mit, Annal. d. Phyfik. L.33. St. 4. J. 1S०9. St. 12. Le 


\section{$\left[\begin{array}{lll}422 & 1\end{array}\right.$}

In den Schriften des Inftituts zu Bologna von Martinelli befchrieben, und auch Saverien redet von demfelben in feinem Dictionnaire de $\mathrm{Ma}$ rine. Die rehler, welche daffelbe hat, giebt Dr. Desagnliers in feinem Cours de Phyfaque an, und befchreibt darin mit grofser Umftändlichkeit mehrere Bathometer von leiner und des Dr. $\mathrm{Ha}$ les Erfindung, welche die Tiefe durch Compre[fion der Luft mefien follten ${ }^{*}$ ); alles ift aber blofs

welche bef:immt waren, die Befchaffenheit des Mecres in groisen Tiefen kennen zu lernen. Im zweiten dieler feiner neuen Bathometer war die Kugel in fenk. rechter Richtung durchböhlt, und in diefer Höhlung eine Spindel vie in den Talcheuthren mit fchief Stehenden Flügeln angebracht, die durch eine Schraube ohne Ende Rüderwerk und Zeiger unttrieb; Io lange das Eathometer im Waller herab fank. So bald das Gewicht fich ablölere, verfchluls eine Feder dic Hüin!ung durch eine Klappe, und das Räderwerb blieb beim Auffchwimmen des Inftruments in Ruhe. Sein dritter und letzter Vorfchlug zu einem Explotctor profurditatis, difruntiae, abyfji, wic cr das Bathometer neunt, bilde ich bier anf Taf. IV, Fig. 2. ah. $A A$ ift die gelirnifste hü:zerne Kugel, $D$ der Suluinmer, und $F F, G G$ find zwei Odnmeter, von denen das cine beim Sirken, das ancere, welches ferade umgekehrt geftellt ift, beim AnfwïrtsCchwimnen des Infiruments umgetrieben wird. An den federnden Halien $C$ wird das Gewiche gehïng, sve!ches das Batiomerer unit herab zieht.

Gibuerc.

*) Auf diefe Idee ivar fchon Hooke geliommea, verliefa fie aber, veil die Comprefíon der Luit in dem luftrumerte nur dana die Tiete melín konnte, wenn man die Temperatur urd die Befchaffenheit des Waffers diefer Tie. fe kannte, und mit Sichericit wufste, dafs das Walfer in Sehr grolsen Tiefen gar nicht comprimirt feg. Dagegen wnllte fich Hooke diefer Vorrichtung als Explorator Gravitationis bediessen.

Gilbers. 


\section{$\left[\begin{array}{lll}42 j & ]\end{array}\right.$}

theoretifch, ohne dafs irgend ein Verfuch den Erfoig bewährt hätte.

In dem Repertory of Arts and Manufactures, Vol. II., Gndet man eine Firfindung eines Künftlers befclirieben, Namens Greenftreet, um das Meer zu fondiren, welche Aehnlichkeit mit dem letzten Explorator des Dr. Hooke hat. An ein langes Strick Holz wird ein Gewicht gehängt, welclies da: Inftrument in das Waffer herab zielit; auf dem obern Ende des Holzes fieht ein Schwimmer, der, wenn das Holz wieder herauf gekommen if, zum Waffer heraus ragt; und in der Mitte des Holzftückes ift eine Art von Schenkel (cuiffe) angebracht, in dem fich cire den Wegemeffern ähnliche Vorrichtung befindet. Diefe befteht aus einer Spirale von $\mathrm{Holz}$, welche von dem Waffer in die Runde getrieben wird, das durch den Schenkel und eino Seitenröhre hindurch ftrömt, während das Inftrument zu Boden finkt. Die Achfe der Spirale endigt fich wit einer Schraube ohne Ende, die in das Räderwerli eingreift, und diefes ift mit Zeigern und Zifferblättern verfehen, welche die Zahl der Umläufe der Spirale zählen. Beim Auffiofsen auf den Mecresbcden ivird ein Stift zwifchen die Zähne des erften Fades gefchoben, und dadurch die fernere Bewegung gehemmt. Hicrbei wird vefentlich erfordert, dafs man durch viele Verfuche das Räderwerk genau der Länge der Achle der Spirale (welche bier die Einheit des

Ee 2 


\section{$\left[\begin{array}{lll}424 & \text { ] }\end{array}\right.$}

Malses ift) proportionirt habe; eine Sache, die fehr fchwer zu erlangen ift.

Herr $L$ uisiius beurtheilt diefes Infrument fehr umftändlich, und zeigt, welche Vorzüge und welche Fehler es hat. Das Bathometer, welches er vorfchlägt, beruht zwar auf einerlei Grundfätzen mit diefem, doch glaubt er es ron den Fehlern des Greenftreeţ'fchen befreiet und demfelben eine gröfsere Vollkommenheit, als allen andern, gegeben zu haben. Ich will verfuchen (fagt Herr L'Esvêque), davon eine fo deutliche Ifee zu geben, als fich ohne Hailfe von Figuren thun lälst.

Das Inftrument befteht aus einem Schivimmer (boué, Boye), 'welche einen Erkennungs-Wimpel (fiamme de reconnailfance) trïgt, aus einem Odometer, und aus einem Gewichte, das entweder einfach und unbeftimmt, oder zufammen gefetzt und von beftimmter Art ift. Die Vor-Sonde, mit welcher Hr. Luisci us vorläufig die fcheinbare Tiefe und die Natur des Meergruades, an der Stelle, wo fondirt werden foll, unterfucht, um danach die Art des Geviclites am Bathometer aus. zuwählen, befteht blofs aus einem Schwimmer mit feinem Erkennungs - Wimpel und aus einem einfachen Gewichte. Der Schwimmer ift ein hohler Cylinder aus ftarkem Kupferblech, der fich oben und unten konifch endigt. Durch die Spitze des untern Koaus geht eine cylindrifcbe Röbre; die Spitze des obern endigt Gch mit einer Schraube, 


\section{[ 425 ]}

an welcher der Wimpelftock (la boice du digon) befeftigt wird, .der eine runde, fenkrecht ftehende, Scleeibe und zuoberft den Wimpel oder die Fahne trägt. Das Gewicht befteht aus einem Cylinder, der fich unten in einem Knopfe endigt, und längs feiner Achfe durchbohrt ift; durch die Achle geht ein ciferner Stab, an den unten eine kupferne Kugel angefchroben ift, und der fich oben wie eine Pike endigt. Diefer Stab bewirkt beim Aufftolsen auf den Grund des Meeres die Ablöfung des Schwimmers von dem Gewichte, und hammt zugléich cien Odoineter, durch einen Mechanismus, der fich ohne Figuren nicht verdeutlichen liifst, den man aber in dem Werke fehr umftändlich befclorieben und in Zeichnungen dargeftellt findet. Durch diefen Mechanismus hauptfächlich unterfcheidet fich das Bathometer des Hrn. $L$ ujscius von den frühern Inftrumenten diefer Art, und hierin ubertrifft es fie durch Zuverläfligkcit der Wirkung. Die grofse Vor-Sonde des Verfaffers entfpricht in fo weit ebenfalls diefer Befchreibung. Das Bathometer unterfcheidet fich von ihr daclurch, dals es mit einem Odometer verfehen ift, wie die ähnlichen Infirumente Hooke's und Greenftreet's. Die Einrichtung der Wegemeffer ift bekannt, daher hier von dem Odometer nicht melir angeführt zu werden braucht, als dafs Herr $\mathbf{L}$ u iscius vier lileine Flïgel an der Spindel Gre en ft re e t's Spirale vorzieht; dafser feine Odometer mit einen fo genannten Moderator verfieht, 


\section{[ 426 ]}

mittelf deffen er fiè nach der vorläufig bekannten Tiefe adjuftirt; dafs er für grofse Tiefen fich eines andern Odometers mit mehr Räderwerk, als für gewühnliche Tiefen, bedient; und dals er durch ein Flechtwerk aus Meffingdraht zu verhinclern fucht, dafs Fifche oder andere Gegenftände den Lauf der kleinen Mühle hindern können. Auch hat er einen Strömungs-Meffer; und da, wo Schlamm, Meerespllanzen, oder Korallen das Bathometer feft halten würden, bringt er einen belondern Mechanismus an, der den Schivimmer in beliebiger Höhe über dem Boden auslöfet. Alles das macht aber das Inftrument, das möglichft einfach feyn fallte, ziemlich zufammen gefetzt.

Herr Luiscius meint, nach angeftellten Verfuclien follte man glauben, Körper fänken im Water eber fo gut als in der Luft mit befchleunigter bewergung zu Boden; bei feinem Bathometer komme cias aber, da die Befchleunigung in einem fo dirteren iviltel, als das Waffer, nur höchft geringe fe jn küone, fo wenig in Anfchlag, dafs man davon ganz ádehen künne, da die Zahl der Umläufe der ringel der Gefcluwindigkeit des Sinkens und ius Dichtigkeit der Flüfligkeit proportional feyn mulfen. Er fuhrt Vorfuche an, die er in diefer Abficht in einer 20 Fufs langen und 4 Zoll weiten Röhre, die er erft mit Brunnenwaffer, dann mit einer vier Mahl ftärliern Salzauflöfung, als das Meerwafler, gcfüllt hatle. Er liefs darin fein Bathometer mit dem gewölalichen, und darauf 


\section{$\left[\begin{array}{lll}427 & 1\end{array}\right.$}

mit einem gröfsern Gewichte herunter finken, und die Angaben der Tiefen wichen um kein Zivanzigftel von einander ab; woraus er fchliefst, dafs unter den gewöhnlichen Umitänden diefe Urlacho nur fehr geringe Fehler veranlaffen kann *).

Regeln über die Art, wie diefes Bathometer zu brauchen ift; befchliefsen clas Werk. In einer Einleitung fpricht Herr Luiscius von der Entfelung der Natur und der Tiefe cler Meere, und erzählt mit vieler Ordinung und Deutlichkeit, was von der Bildung unferer Erde und ceren Theilen, und von den Veränderungen, die fie erlitten haben, bekannt oder a!lgemein argenommen ift.

-) Was Ir. Dr. Ca [tberg in Kopenhagen in diefen Annalen, J. 1805 , St. 3. (B. 19, S. $34+$ E.) über bathnmttrifcho und thermonetrifche Verfuche, die er auf dem Mepre anzuftellen dach:e, vorlüufig bemerkt hat, verdient hiermit verglichen zu werden, ift er gleich durcin die verdienfzvollen Arbeiten, ivelche es fritdem als Director deg Taubftummen-Inftituts ïbernommen hat, an der Ausfübrung diefer Verfiche verhindert worden.

Gilbert. 